\title{
The long and winding road to improving immunization rates: Sharing best practices in Canada
}

\author{
MacDonald, NE ${ }^{\star}$
}

\section{Abstract}

Vaccines are one of the most effective ways to decrease childhood mortality. Unfortunately, however, Canada placed 28th out of 29 high-income countries in a 2013 UNICEF report that compared national uptake rates of early childhood immunizations. Work is underway to address this issue as reflected in the 2016 federal budget which highlights the importance of improving access to immunization. There are many steps that can be taken to improve vaccine uptake, such as identifying and better understanding the individual and program level factors that underlie delay or refusal to receive vaccines. However, it is challenging to find evidence and ensure its relevancy within the Canadian context. Targeted resources are needed that address the complexity of immunization along the entire continuum from vaccine manufacture through to patient uptake. Although there is a lot of information relevant to Canada, it has not been gathered together in one "go to" site and it is not curated. Canada needs a solid, easily accessible, user-friendly platform for sharing what works in immunization with health care professionals as well as parents and patients. This platform would be a major step in facilitating vaccine acceptance in Canada.

Suggested citation: MacDonald, NE. The long and winding road to improving immunization rates: Sharing best practices in Canada. Can Comm Dis Rep 2016;42(12):243-5. https://doi.org/10.14745/ccdr.v42i12a01

\section{Affiliation}

${ }^{1}$ Department of

Pediatrics-Infectious Diseases, Faculty of Medicine, Dalhousie University, Halifax, NS

${ }^{*}$ Correspondence: noni. macdonald@dal.ca

\section{Introduction}

Vaccines are an important tool in decreasing childhood mortality worldwide. They are so important that in 2010, the Global Vaccine Action Plan (GVAP), set forth a vision for the Decade of Vaccines to develop a "framework to prevent millions of deaths by 2020 through more equitable access to existing vaccines for people in all communities". This plan was endorsed by the 194 member states of the World Health Assembly (including Canada) in May 2012 (1). Yet, despite the fact that: vaccines have eradicated smallpox, are closing in on polio, have recently been credited with eliminating indigenous measles in the Americas and are supported by a large body of high quality scientific evidence demonstrating the importance of vaccination throughout the life course; immunization of infants, children, adolescents and adults is neither readily accepted nor demanded by all.

\section{Immunization coverage}

We are now more than half way through the Decade of Vaccines, yet Canada placed a dismal $28^{\text {th }}$ out of 29 high-income countries in the UNICEF Office of Research's Innocenti Report 2013 that compared uptake rates of early childhood immunizations country by country (2). Since many provinces and territories lack robust immunization registries, some experts quibble with the Canadian reported rate of $84 \%$, but none would argue that Canada is anywhere near the over $95 \%$ rates reported for
Finland and several other countries. Strategic Objective 2 of the GVAP states that "individuals and communities understand the value of vaccines and demand immunization as both their right and responsibility" (1). Regardless of whether Canada's early childhood immunization rate was precisely $84 \%$ or not, Canada must do better in terms of vaccine acceptance and vaccine demand not just for early childhood vaccines, but also for adolescent and adult vaccination including immunization for pregnant woman. The congenital rubella case reported in Ontario in late 2015 demonstrates that gaps remain in the fetal rubella protection program which can lead to tragic and lifelong consequences (3).

Improving equity of access to immunization was highlighted in Canada's 2016 federal budget which earmarked \$25 million over five years, starting in $2016 / 17$ so that "the Public Health Agency of Canada will update the national immunization coverage goals and disease reduction targets, improve Canada's ability to identify under- and un-immunized Canadians, and develop a focused program to improve vaccine access and uptake" (4). The recommendations of the 2015 Vaccine Acceptance and Uptake Working Group provide a road map for PHAC on moving forward to address vaccine hesitancy (Unpublished data. Dr. Robert Pless, Public Health Agency of Canada).

\section{Addressing vaccine hesitancy}

Vaccine hesitancy, or "the delay in acceptance or refusal of vaccines despite availability of vaccine services," is a well 
recognized problem in Canada and globally (5). Unfortunately, ensuring timely acceptance of vaccines is not easy for provincial and territorial immunization programs or front line health care professionals. Simply providing information about the benefits of vaccines and the risks of vaccine preventable diseases is not enough $(6,7)$. Overselling by emphasizing the facts about vaccine benefits and disease risks alone may exacerbate hesitancy and diminish on-time vaccine acceptance (8). The article in this issue by Eve Dubé and colleagues emphasizes the complexity of the vaccine hesitancy problem and offers potential intervention and prevention strategies that may be useful in the Canadian context (9). Sadly, there is no "magic bullet" intervention that will address all concerns about vaccine complacency, convenience and confidence hesitancy such that vaccine acceptance would become the norm for all but the very small minority (likely under one to two percent) who are firm vaccine deniers (8).

As noted by Dubé and others, listening to and determining the factors underlying delay or refusal are critical first steps at the individual and program level (9-11). Communication and intervention strategies must be tailored to address the problem. Specific parental and patient concerns need to be addressed whether they are about vaccine safety, vaccine preventable disease risk, fear of needles or other issues. Since vaccine hesitancy is vaccine specific and varies by context, time and place (8), the list of "new" concerns that pop up may seem endless and daunting, especially for front line workers if the needed evidence is not at their fingertips or is in a format that is not relevant to the hesitant parent or adult patient.

It is often difficult to find evidence quickly and ensure its relevancy in the Canadian context. The article in this issue on the "what, where and for whom" of different National Advisory Committee on Immunization (NACl) products offers helpful tips that will move Canada forward (12). For example, there are detailed evidence-based $\mathrm{NACl}$ statements on the PHAC website (13), NACl summaries in the Canada Communicable Disease Report such as the annual seasonal influenza vaccine statement (14) and update on hepatitis A (15) as well as practice-oriented immunization information including chapters on each vaccine in the Canadian Immunization Guide (16). These are all useful, regularly updated and one can subscribe to automatically receive $\mathrm{NACl}$ and $\mathrm{CIG}$ updates (17).

Unfortunately, a "what to find where" article is not enough. Targeted resources addressing the complexity of immunization from vaccine manufacturing to patient receipt are needed. Parents/patients have raised concerns at various points along this long continuum from production to the arm. Concerns about vaccine safety are common. These can undermine trust in the system and augment hesitancy to vaccinate. Canada has a very robust vaccine safety system designed to assure high quality and safe vaccines. There is a high quality vaccine delivery system to provide immunization services to patients and a high quality surveillance system to find adverse events following immunization and determine if these are related to the vaccine or the vaccine program and whether action needs to be taken. Indeed, Canada is a leader in vaccine safety. However, many health care professionals are unaware of the robustness and breadth of the vaccine safety system. The Canadian Paediatric Society Committee on Immunization and Infectious Diseases provides a practical overview of Canada's vaccine safety program that can help front line workers better answer vaccine safety system questions raised by parents/patients (18). The importance of the network of special immunization clinics across the country cannot be overstated. These are staffed by pediatric and adult vaccine specialists who are well experienced in addressing challenging adverse events following immunization and who can help assess and counsel those who have had a serious adverse event following immunization.

\section{Accessing best practices}

The articles in this issue barely scratch the surface regarding the evidence and information needs of immunization program managers and front line health care workers. While much relevant Canadian information is available, it has not been gathered together in one "go to" site and it is not curated. For example, many front line workers may not be aware of the Canadian Paediatric Society's parental advice on risks and responsibilities of vaccination (19). Similarly, immunization program managers are likely unaware of the recently developed WHO EURO guidance on how to address vocal vaccine deniers in public-a task many find very stressful (20). Even basic awareness of these documents does not make them more accessible on the web. Furthermore, there is no simple way to consult an expert when an immunization conundrum arises. Canada does not have an Immunization Action Coalition like the United States that "works to increase immunization rates and prevent disease by creating and distributing educational materials for health professionals and the public that enhance the delivery of safe and effective immunization services" (21). While Immunize Canada is a beginning, it is neither funded nor equipped to provide the breadth of materials, nor the curating activities and ability to respond to immunization query functions needed in Canada (22).

\section{Conclusion}

Canada could be a leader in vaccines rates for children, adolescents, adults and the elderly. We need a more solid, easily accessible, user-friendly platform for health care professionals, parents and patients that will share what works in immunization. Higgledy piggledy information to support a global health priority is not enough. A one-stop platform with useful resources and evidence on best practices would be a major step along the road to supporting improvement in vaccine acceptance in Canada.

\section{Conflict of interest}

None.

\section{References}

1. World Health Organization (WHO). Global Vaccine Action Plan 2011-2020 [Internet]. Geneva: WHO; 2012 [cited 2016 Oct 24]. Available from: http://www.who.int/immunization/ global_vaccine_action_plan/en/.

2. UNICEF Office of Research. Child well-being in rich countries: A comparative overview. Innocenti report card 11 [Internet]. Florence, Italy: UNICEF; 2013 [cited 2016 Oct 
24]. Available from: www.unicef-irc.org/publications/pdf/ rc11_eng.pdf.

3. Government of Canada. Measles and rubella weekly monitoring report: Week 27, 2016: July 3 - July 9, 2016 [Internet]. Ottawa, ON: PHAC; 2016 [cited 2016 Oct 24]. Available from: http://healthycanadians.gc.ca/publications/ diseases-conditions-maladies-affections/measles-rubella-201607-surveillance-rougeole-rubeole/index-eng.php.

4. Government of Canada [Internet]. Growing the middle class: Budget 2016. Chapter 5. An inclusive and fair Canada. Ottawa: Government of Canada; 2016 [updated 2016 Mar 22; cited 2016 Oct 24]. Available from: http://www.budget. gc.ca/2016/docs/plan/ch5-en.html.

5. Strategic Advisory Group of Experts on Immunization (SAGE). Report of the SAGE Working Group on Vaccine Hesitancy [Internet]. Geneva: WHO; 2014 [cited 2016 Oct 24]. Available from: www.who.int/immunization/sage/meetings/2014/ october/SAGE_working_group_revised_report_vaccine_ hesitancy.pdf?ua=1.

6. Jarrett $\mathrm{C}$, Wilson $\mathrm{R}$, O'Leary M, Eckersberger E, Larson $\mathrm{HJ}$ and the SAGE Working Group on Vaccine Hesitancy. Strategies for addressing vaccine hesitancy: A systematic review. Vaccine [Internet]. 2015;33(34):4180-90. Available from: http://ac.elscdn.com/S0264410X15005046/1-s2.0-S0264410X15005046main.pdf?_tid=12c0d644-8667-11e6-b708-00000aacb35f\&acd nat=1475168973_2ff75a5cfd0b5a11b01d61a7669dcda8.

7. Dubé E, Gagnon D, MacDonald NE and the SAGE Working Group on Vaccine Hesitancy. Strategies for addressing vaccine hesitancy: Review of published reviews. Vaccine [Internet]. 2015;33:4191-203. Available from: http://ac.els-cdn.com/ S0264410X15005058/1-s2.0-S0264410X15005058-main.pdf? tid=2fad48be-8667-11 e6-b99c-00000aacb361\&acdnat $=14751$ 69022_993a4854e65a7f9670912ed86d6ac545.

8. MacDonald NE and the SAGE Working Group on Vaccine Hesitancy. Vaccine hesitancy: Definition, scope and determinants. Vaccine [Internet]. 2015;33:4161-4. Available from: http://ac.els-cdn.com/S0264410X15005009/1s2.0-S0264410X15005009-main.pdf?_tid=9bccbd668669-11e6-8a7e-00000aab0f01\&acdnat $=1475170062_{2}$ eee93e145066ae4d4979ef4b566dac94.

9. Dubé E, Bettinger JA, Fisher WA, Hilderman T. Vaccine acceptance, hesitancy and refusal in Canada: Challenges and potential solutions. Can Comm Dis Rep. 2016;42(12):246-51. Available from: http://www.phac-aspc.gc.ca/publicat/ccdrrmtc/16vol42/dr-rm42-12/ar-02-eng.php.

10. Goldstein $S$, MacDonald NE, Guirguis $S$ and the SAGE Working Group on Vaccine Hesitancy. Health communication and vaccine hesitancy. Vaccine [Internet]. 2015;33:4212-4. Available from: http://ac.els-cdn.com/S0264410X1500506X/1s2.0-S0264410X1500506X-main.pdf?_tid=48776cda-866c11e6-8737-00000aacb35f\&acdnat=1475171211_466521448f6 11 aeaf4a32a7ff29c90a1.

11. Butler R, MacDonald NE and the SAGE Working Group on Vaccine Hesitancy. Diagnosing the determinants of vaccine hesitancy in specific subgroups: The Guide to Tailoring Immunization Programmes (TIP). Vaccine [Internet]. 2015;33: 4176-9. Available from: http://ac.els-cdn.com/ S0264410X15005022/1-s2.0-S0264410X15005022-main.pdf? $\mathrm{tid}=335 \mathrm{e} 320 \mathrm{c}-866 \mathrm{c}-11 \mathrm{e} 6-\mathrm{b} 3 \mathrm{ba}-00000 \mathrm{aacb} 35 \mathrm{e} \& \mathrm{acdnat}=14751$ 71175_783d26eb7165aa0b92e6686d404ef8c3.
12. Desai $S$, Tunis M, Stirling $R$, Jensen $C$, Ismail $S$, Baclic $\mathrm{O}$, Lerch R. Immunization guidance products: Different levels of detail for different uses. Can Comm Dis Rep. 2016;42(12):252-5. Available from: http://www.phac-aspc. gc.ca/publicat/ccdr-rmtc/16vol42/dr-rm42-12/ar-03-eng.php.

13. Public Health Agency of Canada [Internet]. National Advisory Committee on Immunization (NACl) Recommendations, Statement and Updates. Ottawa: PHAC; 2016 [updated 2016 Oct 17; cited 2016 Oct 24]. Available from: http://www.phacaspc.gc.ca/naci-ccni/.

14. Gemmill I, Zhao L, Cochrane L. Summary of the National Advisory Committee on Immunization (NACl) Statement on Seasonal Influenza Vaccine for 2016-2017. Can Comm Dis Rep. 2016;42:187-91. Available from: http://www.phac-aspc. gc.ca/publicat/ccdr-rmtc/16vol42/dr-rm42-9/ar-06-eng.php.

15. Henry B, Baclic O, on behalf of the National Advisory Committee on Immunization (NACl). Summary of the National Advisory Committee on Immunization (NACl) Statement Update on the Recommended Use of Hepatitis A Vaccine. Can Comm Dis Rep. 2016;42:193-4. Available from: http://www. phac-aspc.gc.ca/publicat/ccdr-rmtc/16vol42/dr-rm42-9/ar-07eng.php.

16. Public Health Agency of Canada [Internet]. The Canadian Immunization Guide. Ottawa: PHAC; 2016 [updated 2016 Sep 01; cited 2016 Oct 24]. Available from: http:// healthycanadians.gc.ca/healthy-living-vie-saine/immunizationimmunisation/canadian-immunization-guide-canadienimmunisation/index-eng.php.

17. Government of Canada [Internet]. Canadian Immunization Guide update - Mailing list. [updated 2014 May 13; cited 2016 Oct 24]. Available from: http://healthycanadians. gc.ca/healthy-living-vie-saine/immunization-immunisation/ canadian-immunization-guide-canadien-immunisation/emailsubscription-abonnement-courriel-eng.php.

18. Canadian Paediatric Society Infectious Diseases and Immunization Committee. Principal authors: MacDonald NE, Law BJ. (November 15, 2016). Canada's eight-component vaccine safety system: A primer for health care workers [Practice Point]. Retrieved from: http://www.cps.ca/en/ documents/position/vaccine-safety-system.

19. Canadian Paediatric Society (CPS) [Internet]. Vaccination and your child. Ottawa: CPS; 2016 [updated 2016 Sep; cited 2016 Oct 24]. Available from: http://www.caringforkids.cps.ca/ handouts/when-parents-choose-not-to-vaccinate-risks-andresponsibilities.

20. World Health Organization (WHO). Best practice guidance: How to respond to vocal vaccine deniers in public [Internet]. Geneva: WHO; 2016 [cited 2016 Oct 24]. Available from: http://www.euro.who.int/en/health-topics/disease-prevention/ vaccines-and-immunization/publications/2016/best-practiceguidance-how-to-respond-to-vocal-vaccine-deniers-inpublic-2016.243-5

21. Immunization Action Coalition [Internet]. Saint Paul, Minnesota: IAC; 2016 [cited 2016 Oct 24]. Available from: http://www.immunize.org/.

22. Immunize Canada [Internet]. Ottawa: CPHA; 2016 [updated 2016 Sep 22; cited 2016 Oct 24]. Available from: http:// www.immunize.ca/en/default.aspx. 